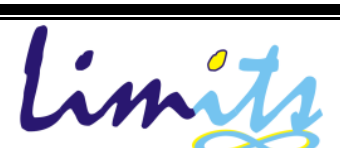

Limits: Journal of Mathematics and Its Applications

E-ISSN: 2579-8936

P-ISSN: 1829-605X

Vol. 17, No. 2, Desember 2020, 97-109

DOI: http://dx.doi.org/10.12962/limits.v17i2.4462

\title{
Teorema Terkait Teknik Perhitungan Integral Garis Lebesgue- Hausdorff atas Kurva Sederhana
}

\author{
Ahmad Lazwardi ${ }^{1}$ *, Rahmatya Nurmeidina ${ }^{2}$ \\ ${ }^{1,2}$ Affiliasi; Jl.H.Syarkawi Banjarmasin \\ 1,2,3 Pendidikan Matematika Universitas Muhammadiyah Banjarmasin \\ e-mail:lazwardiahmad@gmail.com
}

Diajukan:6 Nopember 2018, Diperbaiki: 6 Desember 2020, Diterima:12 Desember 2020

\begin{abstract}
Abstrak
Penelitian ini bertujuan untuk mengkonstruksi beberapa teorema penting untuk teknik integrasi dari integral garis Lebesgue-Hausdorff yang merupakan generalisasi dari integral garis biasa. Hasil dari penelitian ini adalah beberapa teorema yang bersifat teknis yang bisa diaplikasikan dalam menentukan nilai integral garis Lebesgue-Hausdorff dari beberapa fungsi.
\end{abstract}

Kata Kunci: Integral Garis Lebesgue Hausdorff, Ukuran Hausdorff,

\section{Abstract}

This research was purposed to construct an integration technique involving Lebesgue-Hausdorff line integration which is as generalization of usual line integral. The result of this research is some theorems which technically able to determine the value of Lebesgue-Hausdorff line integral of some functions .

Keywords: Lebesgue-Hausdorff line Integral, Hausdorff measure.

\section{Pendahuluan}

Ukuran Hausdorff dan dimensi Hausdorff merupakan konsep yang penting dalam kasus geometri fractal seperti pergerakan Brownian [1]. Istilah ukuran Hausdorff mengacu pada definisi berikut:

Definisi 1[2] Diberikan $\boldsymbol{E} \subset \mathbb{R}^{2}, \boldsymbol{s} \in \mathbb{R}$, ukuran Hausdorff dari himpunan E didefinisikan sebagai

$$
H^{s}(E)=\liminf _{\delta \rightarrow 0}\left\{\sum_{i=1}^{\infty}\left|U_{i}\right|^{s}:\left|U_{i}\right| \leq \delta: E \subset \bigcup U_{i}\right\}
$$

dimana $\left|U_{i}\right|$ adalah diameter $U_{i}$.

Untuk fungsi real dua variabel definisi keterukuran fungsi berdasarkan ukuran Hausdorff masih analog dengan definisi keterukuran fungsi berdasarkan ukuran Lebsegue, sehingga sifatnya tidak banyak berbeda. Meskipun demikian, hal yang perlu diperhatikan adalah dimensi 
Hausdorffnya yang melahirkan beberapa sifat-sifat khusus. Berikut adalah definisi keterukuran fungsi.

Definisi 2[3] Diberikan bilangan $s$ dengan $0 \leq s \leq 2$ dan fungsi $f: E \subset \mathbb{R}^{2} \rightarrow \mathbb{R}$. Fungsi $f$ dikatakan terukur s-Hausdorff jika untuk setiap himpunan terbuka $O \subset R$ berlaku $f^{-1}(O)$ terukur s-Hausdorff.

Teorema di atas berakibat langsung bahwa setiap fungsi kontinu terukur $s$-Hausdorff berapapun nilai $s$.

Lemma 3[4] Diberikan fungsi $f: E \subset \mathbb{R}^{2} \rightarrow \mathbb{R}$. Pernyataan berikut ekuivalen:

(i) Untuk setiap $\alpha \in R$ berlaku $f^{-1}((\alpha, \infty))$ terukur s-Hausdorff.

(ii) Untuk setiap $\alpha \in R$ berlaku $f^{-1}([\alpha, \infty))$ terukur s-Hausdorff.

(iii)Untuk setiap $\alpha \in R$ berlaku $f^{-1}((-\infty, \alpha))$ terukur s-Hausdorff.

(iv)Untuk setiap $\alpha \in R$ berlaku $f^{-1}((-\infty, \alpha])$ terukur s-Hausdorff.

Definisi keterukuran fungsi di atas memberikan konsekuensi langsung berupa teorema berikut

Teorema 4[4] Fungsi $f: E \subset \mathbb{R}^{2} \rightarrow \mathbb{R}$ terukur s-Hausdorff jika dan hanya jika untuk setiap $\alpha \in R$, himpunan $f^{-1}((\alpha, \infty))$ terukur s-Hausdorff.

Teorema selanjutnya merupakan fakta penting untuk menjamin eksistensi integral garis Lebesgue-Hausdorff.

Teorema 5[4] Diberikan kurva $\varphi:[a, b] \rightarrow \mathbb{R}^{2}$ dan fungsi $f: E \subset \mathbb{R}^{2} \rightarrow \mathbb{R}$ sehingga peta dari $\varphi$ termuat di E. Jika $f$ terukur 1-Hausdorff maka restriksinya pada peta kurva $\varphi$ terukur 1Hausdorff.

Bukti: Karena $f$ terukur 1-Hausdorff maka untuk setiap himpunan terbuka $O$ berlaku $f^{-1}(O)$ terukur 1-Hausdorff. Diperhatikan restriksi fungsi $f$ pada peta kurva $\varphi$, yaitu $\left.f\right|_{\varphi[a, b]}: \varphi[a, b] \rightarrow$ $\mathbb{R}$ dengan sifat $\left.f\right|_{\varphi[a, b]}(x, y)=f(x, y)$ untuk setiap $(x, y) \in \varphi[a, b]$. Diambil sebarang himpunan terbuka $O$ pada $\mathbb{R}$. Karena ukuran Hausdorff adalah ukuran Borel (tidak tergantung $s$ ) maka $\left.f\right|_{\varphi[a, b]} ^{-1}(O)=f^{-1}(O) \cap \varphi[a, b]$ himpunan terukur 1-Hausdorff. Jadi restriksinya pada peta kurva $\varphi$ terukur 1 -Hausdorff. 
Selanjutnya didefinisikan fungsi karakteristik dari suatu himpunan $E \subset \mathbb{R}^{2}$.

Definisi 6[4] Diberikan himpunan $E \subset \mathbb{R}^{2}$. Didefinisikan fungsi karakteristik E sebagai

$$
\chi_{E}: \mathbb{R}^{2} \rightarrow \mathbb{R}
$$

dengan

$$
\chi_{E}(x, y)= \begin{cases}1, & (x, y) \in E \\ 0, & (x, y) \notin E\end{cases}
$$

Mudah dibuktikan bahwa keterukuran fungsi karakteristik berlaku jika hanya jika support nya terukur Hausdorff.

Teorema berikut menjelaskan tentang sifat-sifat dari invariansi fungsi terukur Hausdorff.

Teorema 7[4] Diberikan E himpunan terukur s-Hausdorff. Jika $f, g: E \subset \mathbb{R}^{2} \rightarrow \mathbb{R}$ terukur sHausdorff dan $c \in \mathbb{R}$, maka $f+c, c f, f+g, g-f$ dan fg terukur $s$-Hausdorff.

Catatan: dalam hal ini fungsi $c$ didefinisikan sebagai $c(x, y)=c$ untuk setiap $(x, y) \in E$.

Teorema 8[4] Diberikan barisan fungsi terukur s-Hausdorff dan koleksi fungsi $\left\{f_{n}: E \subset \mathbb{R}^{2} \rightarrow\right.$ $\mathbb{R}\}$ berlaku $f^{*}=\sup f_{n}$ dan $f_{*}=\inf f_{n}$ terukur s-Hausdorff.

Teorema berikutnya adalah teorema yang sangat penting dalam mempermudah perhitungan nilai integral Lebesgue-Hausdorff.

Teorema 9[4] Diberikan fungsi $f, g: E \subset \mathbb{R}^{2} \rightarrow \mathbb{R}$ dan $f$ terukur s-Hausdorff. Jika $f=g$ a.e maka g terukur s-Hausdorff.

\section{Bukti:}

Misalkan $A=\{(x, y) \in \mathrm{E}: f(x, y) \neq g(x, y)\}$. Karena $f=g$ a.e pada $E$, maka $H^{S}(A)=0$.

Diambil sebarang $\alpha \in \mathbb{R}$. Diperoleh bahwa

$$
\{x \in E \mid g(x)>\alpha\}=[\{x \in E \mid f(x)>\alpha\} \cup\{x \in A \mid g(x)>\alpha\}]-\{x \in A \mid g(x) \leq \alpha\}
$$

Karena $f$ terukur $s$-Hausdorff maka $\{x \in \mathrm{A} \mid g(x)>\alpha\}$

Karena $H^{S}(A)=0$, dan

$$
\{x \in A \mid g(x)>\alpha\},\{x \in A \mid g(x) \leq \alpha\} \subseteq A
$$

maka, $\{x \in A \mid g(x)>\alpha\}$ dan $\{x \in A \mid g(x) \leq \alpha\}$ terukur $s$-Hausdorff. Akibatnya, $\{x \in E \mid g(x)>\alpha\}$ terukur $s$-Hausdorff, $\forall \alpha \in \mathbb{R}$.

Jadi terbukti, $g$ terukur $s$-Hausdorff terbukti. 
Sebelum mendefinisikan integral garis Lebesgue-Hausdorff, terlebih dahulu diberikan definisi fungsi sederhana sebagai berikut.

Definisi 10[4] Diberikan $E$ himpunan terukur s-Hausdorff. Suatu fungsi real $\psi: E \subset \mathbb{R}^{2} \rightarrow \mathbb{R}$ disebut fungsi s-sederhana jika ada berhingga himpunan terukur s-Hausdorff saling asing $\left\{E_{1}, E_{2}, \ldots, E_{p}\right\}$ sehingga $E=\cup_{k=1}^{p} E_{k}$ dan berhingga bilangan real berbeda $a_{1}, a_{2}, \ldots, a_{p}$ sehingga

$$
\psi(x)=\sum_{k=1}^{p} a_{k} x_{E_{k}}
$$

Selanjutnya siap untuk didefinisikan integral garis Lebesgue-Hausdorff untuk kurva injektif rektifiabel sebagai berikut.

Definisi 11[4] Diberikan kurva injektif rektifiabel $\varphi:[a, b] \rightarrow \mathbb{R}^{2}$ dan fungsi 1-sederhana $\psi: \varphi[a, b] \rightarrow \mathbb{R}$ sehingga

$$
\psi(x)=\sum_{k=1}^{p} a_{k} x_{E_{k}}
$$

untuk suatu himpunan terukur 1-Hausdorff saling asing $\left\{E_{1}, E_{2}, \ldots, E_{p}\right\}$ dengan $\varphi[a, b]=\bigcup_{k=1}^{p} E_{k}$ dan bilangan real berbeda $a_{1}, a_{2}, \ldots, a_{p}$.

Didefinisikan integral garis Lebesgue-Hausdorff dari $\psi$ sebagai

$$
(L H) \int_{\varphi} \psi d H=\sum_{k=1}^{p} a_{k} H^{1}\left(\chi_{E_{k}}\right)
$$

Karena domain dari fungsi sederhana merupakan gabungan berhingga dari himpunan-humpunan yang terukur $s$-Hausdorff maka fungsi sederhana selalu terukur $s$-Hausdorff untuk $0 \leq s \leq 2$. Dapat dilihat dari definisi di atas, konsep fungsi karakteristik dan fungsi sederhana dengan domain kurva rektifiabel tidak jauh berbeda dengan konsep fungsi sederhana secara umum, hanya saja ukuran yang dipakai adalah ukuran Hausdorff dan domainnya berupa peta kurva.

Perlu diingat disini, integral garis Lebesgue-Hausdorff untuk sebarang fungsi sederhana pasti eksis dan berhingga mengingat sifat subadditif dari ukuran Hausdorff dan $H^{1}(\varphi[a, b])=$ $L(\varphi)<\infty$. Lebih jauh integral garis fungsi sederhana bersifat linear dan naik monoton. 
Teorema 12[4] (Lemma Aproksimasi Fungsi Sederhana) Diberikan $0<s \leq 2$ dan fungsi terukur $s$-Hausdorff $f: E \subset \mathbb{R}^{2} \rightarrow \mathbb{R}$. Jika $f$ terbatas maka untuk setiap $\varepsilon>0$ ada fungsi $s$ sederhana $\zeta_{\varepsilon}$ dan $\psi_{\varepsilon}$ sehingga $\zeta_{\varepsilon} \leq f \leq \psi_{\varepsilon}$ dan $\psi_{\varepsilon}-\zeta_{\varepsilon}<\varepsilon$ pada $E$.

Bukti: Karena $f$ terbatas maka dapat dipilih interval $(c, d)$ yang memuat $f(E)$. Diambill sebarang partisi $c=y_{0}<y_{1}<y_{2}<\cdots<y_{n}=d$ sehingga $y_{i+1}-y_{i}<\varepsilon$

untuk setiap $i$. Didefinisikan $I_{i}=\left[y_{i}, y_{i+1}\right)$ dan $E_{i}=f^{-1}\left(I_{i}\right)$. Sebagai konsekuensinya diperoleh $E_{i}$ himpunan terukur $s$-Hausdorff. Didefinisikan fungsi sederhana

$$
\varsigma_{\varepsilon}=\sum_{i=0}^{n} y_{i} \chi_{E_{i}} \text { dan } \varsigma_{\varepsilon}=\sum_{i=0}^{n} y_{i+1} \chi_{E_{i}} .
$$

Mudah dicek bahwa $\zeta_{\varepsilon} \leq f \leq \psi_{\varepsilon}$ dan $\psi_{\varepsilon}-\zeta_{\varepsilon}<\varepsilon$ pada $E$.

Selanjutnya siap untuk didefinisikan integral garis Lebesgue-Hausdorff untuk fungsi terukur Hausdorff sebagai berikut:

Definisi 13[4] (Integral Garis Lebesgue-Hausdorff) Diberikan kurva injektif $\varphi:[a, b] \rightarrow \mathbb{R}^{2}$ dan fungsi $f: \mathbb{R}^{2} \rightarrow \mathbb{R}$. Didefinisikan Integral Bawah Garis Lebesgue-Hausdorff sebagai:

$$
(L H) \int_{\underline{\varphi}} f d H=\sup \left\{(L H) \int_{\varphi} \zeta d H: \zeta \leq f, \zeta \text { fungsi } 1-\operatorname{sederhana~pada} \varphi[a, b]\right\}
$$

Didefinisikan pula Integral Atas Garis Lebesgue-Hausdorff sebagai:

$$
(L H) \int^{\bar{\varphi}} f d H=\inf \left\{(L H) \int_{\varphi} \psi d H: f \leq \psi, \psi \text { fungsi } 1-\operatorname{sederhana~pada} \varphi[a, b]\right\}
$$

Fungsi f dikatakan terintegral garis Lebesgue-Hausdorff jika berlaku

$$
(L H) \int_{\underline{\varphi}} f d H=(L H) \int^{\bar{\varphi}} f d H<\infty
$$

Integral garis Lebesgue-Hausdorff didefinisikan sebagai

$$
(L H) \int_{\varphi} f d H(L H) \int_{\underline{\varphi}} f d H=(L H) \int^{\bar{\varphi}} f d H
$$

Teorema berikut menjelaskan tentang suatu syarat cukup yang menjamin eksistensi integral garis Lebesgue-Hausdorff.

Krzysztof menjelaskan dalam papernya bahwa setiap kurva rektifiabel terukur 1-Hausdorff [5]. Teorema berikut menjelaskan lebih lanjut terkait hubungan antara kurva terukur dengan fungsi terukur 1-Hausdorff. 
Teorema 14[4] Diberikan kurva injektif $\varphi:[a, b] \rightarrow \mathbb{R}^{2}$ dan fungsi terbatas $f: \mathbb{R}^{2} \rightarrow \mathbb{R}$. Jika fungsi f terukur 1-Hausdorff pada $\varphi[a, b]$ maka ferintegral garis Lebesgue-Hausdorff.

Bukti: Andaikan $f$ terukur 1-Hausdorff pada $\varphi[a, b]$ maka untuk setiap bilangan asli $n$ dapat dipilih fungsi 1-sederhana

$$
\varsigma_{n}=\sum_{i=0}^{n} y_{i} \chi_{E_{i}} \operatorname{dan} \psi_{n}=\sum_{i=0}^{n} y_{i+1} \chi_{E_{i}} .
$$

sehingga $\zeta_{\varepsilon} \leq f \leq \psi_{\varepsilon}$ dan $\psi_{\varepsilon}-\zeta_{\varepsilon}<\frac{1}{n}$ pada $\varphi[a, b]$. Akibatnya

$$
0 \leq(L H) \int_{\varphi} \psi_{n}-(L H) \int_{\varphi} \varsigma_{n}=\sum_{i=0}^{n}\left(y_{i+1}-y_{i}\right) H^{1}\left(E_{i}\right)<\frac{H^{1}(\varphi[a, b])}{n}
$$

akibatnya

$$
0 \leq \inf (L H) \int_{\varphi} \psi_{n} d H-\sup (L H) \int_{\varphi} \varsigma_{n} d H<\frac{H^{1}(\varphi[a, b])}{n} \text { untuk setiap } n
$$

Dengan membuat $n$ membesar menuju tak hingga diperoleh

$$
(L H) \int_{\underline{\varphi}} f d H=(L H) \int^{\bar{\varphi}} f d H .
$$

Sebelum membahas tentang kurva sederhana, terlabih dahulu dibahas tentang suatu contoh dari kurva sederhana yang sangat penting, yaitu simpul (loop). Simpul adalah kurva yang tidak mengandung potongan dan titik awalnya sama dengan titik ujungnya. Secara matematis dijelaskan sebagai berikut.

Definisi 15 Suatu kurva $\varphi:[a, b] \rightarrow \mathbb{R}^{2}$ disebut simpul jika $\varphi(a)=\varphi(b)$.

Diperhatikan hal berikut untuk suatu simpul $\varphi:[a, b] \rightarrow \mathbb{R}^{2}$. Diperhatikan hal berikut, interval $(a, b]$ bisa dituliskan sebagai $(a, b]=\bigcup_{m=1}^{\infty} \cup\left[\begin{array}{c}\infty \\ n=1\end{array} a+\frac{m}{n}, b\right]$ dengan $\left[a+\frac{m}{n}, b\right]=\phi$ jika $a+\frac{m}{n}>b$. Akibatnya $\varphi(a, b]=\varphi\left(\bigcup_{m=1}^{\infty} \cup_{n=1}^{\infty}\left[a+\frac{m}{n}, b\right]\right)$ sehingga restriksi kurva $\varphi$ pada $\left[a+\frac{m}{n}, b\right]$ injektif asalkan $\left[a+\frac{m}{n}, b\right] \neq \phi$. Selanjutnya karena $\varphi[a, b]=\varphi(a, b] \cap \varphi(\{a\})^{c}$ dan $H^{1}(\varphi(\{a\}))=0$ maka $\varphi[a, b]$ terukur Hausdorff. Dengan fakta ini, bisa diperluas cakupan integral LebesgueHausdorff untuk simpul.

Definisi 16 Suatu kurva $\varphi:[a, b] \rightarrow \mathbb{R}^{2}$ dikatakan sederhana jika restriksinya pada $(a, b)$ merupakan pemetaan injektif.

Dari definisi di atas sudah jelas bahwa setiap simpul dan kurva injektif adalah kurva sederhana. 
Definisi 17[4] Diberikan kurva sederhana $\varphi:[a, b] \rightarrow \mathbb{R}^{2}$ dan fungsi 1-sederhana $\psi: \varphi[a, b] \rightarrow$ $\mathbb{R}$ sehingga

$$
\psi(x)=\sum_{k=1}^{p} a_{k} x_{E_{k}}
$$

untuk suatu himpunan terukur 1-Hausdorff saling asing $\left\{E_{1}, E_{2}, \ldots, E_{p}\right\}$ dengan $\varphi[a, b]=\bigcup_{k=1}^{p} E_{k}$ dan bilangan real berbeda $a_{1}, a_{2}, \ldots, a_{p}$.

Didefinisikan integral garis Lebesgue-Hausdorff dari $\psi$ sebagai

$$
(L H) \int_{\varphi} \psi d H=\sum_{k=1}^{p} a_{k} H^{1}\left(\chi_{E_{k}}\right) .
$$

Selanjutnya siap untuk didefinisikan integral garis Lebesgue-Hausdorff untuk fungsi terukur Hausdorff sebagai berikut:

Definisi 18[4] (Integral Garis Lebesgue-Hausdorff) Diberikan kurva sederhan $\varphi:[a, b] \rightarrow \mathbb{R}^{2}$ dan fungsi yang restriksinya pada $\varphi[a, b]$ terukur 1 -Hausdorff $f: \mathbb{R}^{2} \rightarrow \mathbb{R}$.dan terbatas pada $\varphi[a, b]$. Didefinisikan Integral Bawah Garis Lebesgue-Hausdorff sebagai

$$
(L H) \int_{\underline{\varphi}} f d H=\sup \left\{(L H) \int_{\varphi} \zeta d H: \zeta \leq f, \zeta \text { fungsi } 1-\operatorname{sederhana~pada} \varphi[a, b]\right\}
$$

Didefinisikan pula Integral Atas Garis Lebesgue-Hausdorff sebagai:

$(L H) \int^{\bar{\varphi}} f d H=\inf \left\{(L H) \int_{\varphi} \psi d H: f \leq \psi, \psi\right.$ fungsi $\left.1-\operatorname{sederhana~pada} \varphi[a, b]\right\}$

Integral garis Lebesgue-Hausdorff didefinisikan sebagai

$$
(L H) \int_{\varphi} f d H(L H) \int_{\underline{\varphi}} f d H=(L H) \int^{\bar{\varphi}} f d H
$$

Lintasan adalah perumuman dari konsep kurva. Dengan memperumum konsep integral Lebesgue-Hausdorff sehingga berlaku pada sebarang lintasan, konsep integral LebesgueHausdorff mempunyai cakupan yang lebih luas dari integral garis Riemann. Untuk melakukannya, terlebih dahulu dibahas konsep lintasan sebagai berikut.

Definisi 19 Diberikan interval $[a, b] \subset \mathbb{R}$. Lintasan pada $[a, b]$ adalah himpunan berhingga kurva-kurva sederhana

$$
\mathcal{M}=\left\{\varphi_{i}:\left[x_{i-1}, x_{i}\right] \rightarrow \mathbb{R}:\left\{a=x_{0}<x_{2}<\cdots<x_{i}<\cdots<x_{n}=b\right\}\right.
$$


Dalam beberapa pembahasan dimana titik titik partisi tidak diperhatikan,maka untuk menyederhanakan penulisan, cukup ditulis lintasan $\mathcal{M}=\left\{\varphi_{1}, \varphi_{2}, \ldots, \varphi_{n}\right\}$ pada $[a, b]$ untuk mewakili definisi di atas.

Definisi 20 Diberikan interval $[a, b] \subset \mathbb{R}$. dan lintasan $\mathcal{M}=\left\{\varphi_{1}, \varphi_{2}, \ldots, \varphi_{n}\right\}$ pada $[a, b]$. Untuk setiap fungsi yang restriksinya pada $\mathcal{M}$ terukur 1-Hausdorff $f: \mathbb{R}^{2} \rightarrow \mathbb{R}$.dan terbatas pada $\mathcal{M}$. Didefinisikan Integral Garis Lebesgue-Hausdorff sebagai:

$$
(L H) \int_{\mathcal{M}} f d H=\sum_{k=1}^{n}(L H) \int_{\varphi_{k}} f d H
$$

\section{Metode Penelitian}

Metode penelitian ini menggunakan metode kajian pustaka dengan tahapan sebagai berikut. Pertama dipelajari konsep ukuran Hausdorff dan karakteristiknya yang analog dengan ukuran Lebesgue. Setelah menemukan beberapa kesamaan sifat, dilanjutkan dengan generalisasi sifat ukuran Lebesgue kepada ukuran Hausdorff. Selanjutnya didefinisikan integral garis Lebesgue-Hausdorff beserta syarat cukupnya untuk kurva injektif. Kemudian definisi integral garis Lebesgue-Hausdorff digeneralisasi untuk sebarang kurva sederhana dan sebarang lintasan. Tahap akhir penelitian ini adalah merumuskan teorema-teorema yang bisa dimanfaatkan sebagai teknik integrasi untuk mempermudah perhitunagn integral garis Lebesague-Hausdorff.

\section{Hasil dan Pembahasan}

Pada subbab ini diberikan beberapa teori yang bisa mempermudah perhitungan nilai Integral Hausdorff. Pembahasan ini dimulai dengan membandingkan nilai integral garis Lebesgue-Hausdorff dengan integral garis biasa. Hal ini dipaparkan dalam teorema berikut.

Teorema 21 Diberikan $\varphi:[a, b] \rightarrow \mathbb{R}^{2}$ kurva sederhana. Jika f terintegral garis Riemann pada $\varphi[a, b]$ maka f terintegral garis Lebesgue-Hausdorff pada $\varphi[a, b]$. Lebih jauh, integral garis Lebesgue-Hausdorff nya sama nilainya dengan integral garis Riemann.

Bukti: Diperhatikan hal berikut.

$$
\begin{aligned}
(L H) \underbrace{}_{\underline{\varphi}} f d H & =\sup \left\{(L H) \int_{\varphi} \varsigma d H: \varsigma \leq f, \varsigma \text { fungsi sederhana pada } \psi[a, b]\right\} \\
& \geq \sup \left\{\int s: s=\sum_{k=1}^{n} \alpha_{k} \chi_{I_{k}}, s \leq f,\left\{I_{k}\right\} \text { path sepanjang } \psi[a, b]\right\}
\end{aligned}
$$




$$
\geq \sup \left\{\sum_{k=1}^{n} m_{k} \sqrt{\frac{d x(t)}{d t}+\frac{d y(t)}{d t}}\left(t_{k-1}-t_{k}\right), t \in\left(t_{k-1}, t_{k}\right],\left\{\left(t_{k-1}, t_{k}\right]\right\} \text { partisi }[a, b]\right\}
$$

dengan $m_{k}=\inf _{t \in J k} f(x(t), y(t))$

$$
=U_{\varphi}\left(f,\left\{\left(t_{k-1}, t_{k}\right]\right\}\right)
$$

Di sisi lain

$$
\begin{aligned}
&(L H) \int^{\bar{\varphi}} f d H=\inf \left\{(L H) \int_{\varphi} \psi d H: f \leq \psi, \varsigma \text { fungsi sederhana pada } \psi[a, b]\right\} \\
& \geq \inf \left\{\int s: s=\sum_{k=1}^{n} \alpha_{k} \chi_{I_{k}}, f \leq s,\left\{I_{k}\right\} \text { path sepanjang } \psi[a, b]\right\} \\
& \geq \inf \left\{\sum_{k=1}^{n} M_{k} \sqrt{\frac{d x(t)}{d t}+\frac{d y(t)}{d t}}\left(t_{k-1}-t_{k}\right), t \in\left(t_{k-1}, t_{k}\right],\left\{\left(t_{k-1}, t_{k}\right]\right\} \text { partisi }[a, b]\right\} \\
& \text { dengan } M_{k}=\sup _{t \in J k} f(x(t), y(t)) \\
&=L_{\varphi}\left(f ;\left\{\left(t_{k-1}, t_{k}\right]\right\}\right) .
\end{aligned}
$$

Karena f terintegral garis Riemann maka diperoleh

$U_{\varphi}\left(f ;\left\{\left(t_{k-1}, t_{k}\right]\right\}\right)=L_{\varphi}\left(f ;\left\{\left(t_{k-1}, t_{k}\right]\right\}\right)$.

Karena hal tersebut berlaku untuk sebarang partisi maka

$$
\int_{\underline{\varphi}} f d A=(L H) \int_{\underline{\varphi}} f d H=(L H) \int^{\bar{\varphi}} f d H=\int^{\bar{\varphi}} f d A
$$

Dengan $\int_{\underline{\varphi}} f d A$ dan $\int^{\bar{\varphi}} f d A$ berturut-turut adalah integral bawah garis Riemann dan integral atas garis Riemann

Teorema di atas memberikan konsekuensi langsung berupa akibat berikut.

Akibat 22 Diberikan lintasan $\mathcal{M}=\left\{\varphi_{1}, \varphi_{2}, \ldots, \varphi_{n}\right\}$ pada $[a, b]$. Jika f terintegral garis Riemann pada $\mathcal{M}$ maka ferintegral garis Lebesgue-Hausdorff pada $\mathcal{M}$. Lebih jauh, integral garis Lebesgue-Hausdorff nya sama nilainya dengan integral garis Riemann.

Berdasarkan teorema di atas, dapat disimpulkan teknik integrasi pertama adalah jika suatu fungsi terintegral garis Riemann, maka cukup untuk menghitung nilai integral garis Riemann untuk menentukan nilai integral garis Lebesgue-Hausdorff nya. Setiap fungsi yang terintegral garis Riemann, fungsi tersebut terintegral garis Lebesgue-Hausdorff, tapi tidak berlaku sebaliknya. 
Contoh fungsi tersebut dijelaskan di akhir pembahasan. Teknik integrasi selanjutnya berfokus pada teknik perhitungan integral Garis Hausdoff-Lebesgue yang tidak terintegral Riemann.

Teorema 23 Diberikan $\varphi:[a, b] \rightarrow \mathbb{R}^{2}$ kurva sederhana dan fungsi terintegral Garis Riemann $f: \varphi[a, b] \rightarrow \mathbb{R}$. Jika $g: \varphi[a, b] \rightarrow \mathbb{R}$ dengan $f=g$ a.e maka fungsi $g$ terintegral garis Lebesgue-Hausdorff dan berlaku

$$
(L H) \int_{\varphi} g d H=\int_{\varphi} f d A
$$

\section{Bukti:}

Karena $f=g$ a.e maka terdapat himpunan $E=\{(x, y) \in \varphi[a, b]: f(x, y) \neq g(x, y)\}$ dengan $H^{1}(E)=0$.

Akibatnya untuk setiap fungsi sederhana pada $\varphi[a, b]$

$$
\psi(x)=\sum_{k=1}^{p} a_{k} x_{E_{k}}
$$

berlaku $H^{1}(\varphi[a, b]-E)=H^{1}\left(\bigcup_{k=1}^{p} E_{k}-E\right)$

$$
=H^{1}(\varphi[a, b])
$$

sehingga $(L H) \int_{\varphi} \psi d H=\sum_{k=1}^{p} a_{k} H^{1}\left(E_{k}\right)=\sum_{k=1}^{p}\left(a_{k} H^{1}\left(E_{k}\right)-a_{k} H^{1}(E)\right)$. Akibatnya

$$
\begin{aligned}
(L H) \int_{\underline{\varphi}} g d H & =\sup \left\{(L H) \int_{\varphi} \psi d H: \psi \text { fungsi sederhana } \psi \leq g\right\} \\
& =\sup \left\{\sum_{k=1}^{p} a_{k}\left(H^{1}\left(E_{k}\right)-H^{1}(E)\right): \sum_{k=1}^{p} a_{k} \chi_{E_{k}} \leq g\right\} \\
& =\sup \left\{\sum_{k=1}^{p} a_{k}\left(H^{1}\left(E_{k}\right)\right): \sum_{k=1}^{p} a_{k} \chi_{E_{k}} \leq f\right\} \\
& =\sup \left\{\sum_{k=1}^{p} a_{k}\left(H^{1}\left(E_{k}\right)\right): \psi \text { fungsi sederhana } \psi \leq f\right\} \\
& =(L H) \int_{\varphi} f d H \\
& =\int_{\varphi} f d A
\end{aligned}
$$


Dengan cara yang analog mudah diperoleh bahwa

$$
(H L) \int_{\varphi} g d H=\int_{\varphi} f d A
$$

Perlu dicatat bahwa teorema di atas masih berlaku jika syaratnya diperlemah menjadi fungsi $f$ terintegral Lebesgue-Hausdorff. Selanjutnya diberikan definisi berikut.

Definisi 24 Diberikan $\varphi:[a, b] \rightarrow \mathbb{R}^{2}$ kurva sederhana dan fungsi $f: \varphi[a, b] \rightarrow \mathbb{R}$ yang terintegral garis Riemann sepanjang $\varphi$. Suatu fungsi $g: \varphi[a, b] \rightarrow \mathbb{R}$ dikatakan bersimulasi-f ( $f$-simulated) jika $g$ terintegral garis Riemann dan $f=g$ a.e. Dalam hal ini fungsi $f$ disebut fungsi simulator dari $g$.

Berikut adalah contoh penerapan integral garis Lebesgue-Hausdorff menggunakan teorema di atas. Sebuah drum berbentuk silinder dengan diameter 1 satuan diberi tanda tertentu berupa garis lurus memanjang pada salah satu sisi drum tersebut. Drum tersebut digelindingkan dari dump truk sejauh $\frac{1}{2}$ rotasi kemudian jatuh ke tanah.

Pergerakan tanda garis pada drum mempunyai model matematis menyerupai sikloid fungsi dua variabel

$$
f(\theta, y)=\frac{1}{2} \sqrt{(1-\sin \theta)^{2}+(1-\cos \theta)^{2}}, \theta<\pi
$$

dengan $\theta$ adalah besar sudut yang dibentuk antara jari-jari dengan ujungnya dengan garis tinggi silinder saat menggelinding. Perpindahan posisi garis yang dipengaruhi torsi drum saat jatuh membuat nilai $f$ sulit untuk ditentukan. Variabel $y$ adalah variabel yang mengukur untuk tinggi silinder. Pergerakan tanda garis berlangsung secara kontinu hingga pada saat $\theta=\pi$ drum bergerak jatuh. Model matematisnya berupa kurva $\varphi:[0, \pi] \rightarrow \mathbb{R}$ dengan $\varphi(\theta)=\theta$. Fungsi $f$ di atas merupakan fungsi yang ekuivalen hampir dimana-mana dengan

$$
g(\theta, y)= \begin{cases}\frac{1}{2} \sqrt{(1-\sin \theta)^{2}+(1-\cos \theta)^{2}} & \theta<\pi \\ 0 & \theta \geq \pi\end{cases}
$$

sehingga nilai dari $(L H) \int_{\varphi} f=\int_{\varphi} g d A$, teknik perhitungan dapat diselesaikan menggunakan kalkulus sederhana.

Definisi di atas memberikan inspirasi untuk mendefinisikan relasi berikut. 
Definisi 25 Diberikan $\varphi:[a, b] \rightarrow \mathbb{R}^{2}$ kurva sederhana dan fungsi $f: \varphi[a, b] \rightarrow \mathbb{R}$ yang terintegral garis Riemann sepanjang $\varphi$. Fungsi $g, h: \varphi[a, b] \rightarrow \mathbb{R}$ dikatakan ekuivalen-f, disimbolkan dengan

$$
g \approx_{f} h
$$

jika dan hanya jika fungsi g dan h sama-sama bersimulasi-f.

Mudah dibuktikan bahwa relasi di atas merupakan relasi ekuivalensi. Selanjutnya terkait dengan karakteristik fungsi yang bersimulasi- $f$ yang sudah dijelaskan di atas, dihasilkan teorema berikut.

Teorema 26 Diberikan $\varphi:[a, b] \rightarrow \mathbb{R}^{2}$ kurva sederhana dan fungsi $g, h: \varphi[a, b] \rightarrow \mathbb{R}$. Jika terdapat fungsi $f: \varphi[a, b] \rightarrow \mathbb{R}$ sehingga $g \approx_{f} h$ maka baik $g$ maupun $h$ sama-sama terintegral Lebesgue-Hausdorff dan berlaku

$$
(L H) \int_{\varphi} g d H=(L H) \int_{\varphi} h d H
$$

Teorema di atas merupakan dasar dari teknik integrasi selanjutnya. Jika suatu fungsi yang akan dicari integral garisnya mempunyai fungsi simulator, maka cukup dihitung nilai integral garis dari fungsi simulator tersebut.

Berikut adalah contoh integral garis Lebesgue-Hausdorff suatu fungsi tidak terintegral garis Riemann.

Diberikan kurva $\varphi:[0,1] \rightarrow \mathbb{R}^{2}$ dengan rumus $\varphi(t)=(t, 2 t)$ untuk $t \in[0,1]$. Diberikan fungsi

$$
g(x, y)= \begin{cases}0 j i k a(x, y) \in \mathbb{Q} \times \mathbb{Q} \\ x \quad \text { lainnya }\end{cases}
$$

Diambil sebarang $\alpha \in \mathbb{R}$. Himpunan $\{(x, y): g(x, y)>\alpha\}=(\mathbb{Q} \cap(\alpha, \infty)) \times(\mathbb{Q} \cap(\alpha, \infty))$. Berdasarkan teorema Tonelli-Fubini, diperoleh $g$ terukur Hausdorff. Diperhatikan fungsi $f(x, y)=x$ untuk $(x, y) \in \mathbb{R}^{2}$. Jelas bahwa $g=f$ a.e dan fungsi $f$ terintegral garis Riemann. Akibatnya integral garis $g$ sepanjang kurva $\varphi$ sama dengan integral garis $f$ sepanjang kurva $\varphi$. Perhitungan secara teknik dapat diselesaikan dengan mudah menggunakan kalkulus sederhana.

Dua teknik integrasi di atas dapat dengan mudah diperumum untuk integral garis sepanjang lintasan.

\section{Simpulan}

Bersarkan pemaparan teori di atas disimpulkan bahwa:

a. Setiap fungsi multivariabel yang terintegral garis Riemann, terintegral garis LebsegueHausdorff, lebih lanjut, nilai kedua integral tersebut sama. 
b. Setiap fungsi multivariabel yang dapat ditemukan fungsi simulatornya, fungsi tersebut terintegral garis Lebsegue-Hausdorff dan nilainya sama dengan nilai integral garis fungsi simulatornya.

\section{Daftar Pustaka}

[1] R. Balka and A. Mathe, "Generalized Hausdorff Measure for Generic Compect Sets," Ann. Acad. Sci. Fenn. Math., vol. 38, no. 72655, pp. 1-8, 2013.

[2] M. Fernandez and G.Sanchez, "Fractal dimension for fractal structures : A Hausdorff approach revisited," Elsevier: Journal of Mathematical Analysis and Applications, vol. 401, pp. 321-330, 2013.

[3] E. Gariepy, C, Measure theory and fine properties of functions, Revisited. United States: CRC Press, 2015.

[4] A. Lazwardi, "Lebesgue-Hausdorff Line Integral of Husdorff Measurable Multivariable Function over Simple Curve on $[a, b]$,'International Conference of Mathematical Analysis, Its Applications and Learning 2018 Proceedings, Yogyakarta, 2018.

[5] K. Ciesielski and T. Glatzer, "Functions Continous on Twice Differentiable Curves, Discontinous on Large Sets,” Real Anal. Exch., vol. 37, pp. 353-362, 2011. 